folk/ed. Derg, 2022; 28(1)-109. sayı

DOI: $10.22559 /$ folklor.1896

\title{
Asmaları Ağlatan Kadınlar: Menopoz Geçiş Döneminde Kara Talihin Ritüel Transferi
}

\author{
The Women Who Make Vine Trees Cry: \\ Transfer of Evil in Menopause Transition Ritual
}

Hicran Karataş*

Öz

İnsan hayatı bir insanlık halinden diğerine geçişi temsil eden dönemlerden oluşur. Bu dönemler hayatın fizyolojik, zihinsel, duygusal ve sosyal dönüm noktalarıdır. İnsanın geçiş dönemlerinin eşiğinde yüzleştiği kırılganlık, savunmasızlık onu sosyal ve doğaüstü alan tarafından desteklenmek, onaylanmak için ritüeller tasarlamaya sevk eder. Ne var ki toplumlar genellikle fizyolojinin en gözde evrelerine eşlik eden geçiş dönemi ritüelleri icat eder ve sosyal onaylama ile performansı teşvik eder. Bununla birlikte kültür bireyin ihtiyaçlarını karşılayan sistem olduğuna göre, menopoz ritüellerinin keşfini ve performansını gerektiren sosyal ihtiyaçlar

Geliş tarihi (Received): 12-07-2021 - Kabul tarihi (Accepted): 4-01-2022

* Dr., Öğr. Üyesi, Bartın Üniversitesi Edebiyat Fakültesi Sosyoloji Bölümü (Bartın University Faculty of Letters Department of Sociology) Turkey. hkaratas@bartin.edu.tr. ORCID 0000-0002-4134-9159 
vuku bulmuş olmalıdır. Bu araştırmanın konusu geçmişte halk hekimliği alanında işlev karşılayan asma ağlatma ritüelinin, menopoz geçiş dönemi ritüeline dönüşmesi sürecidir. Araştırmanın savı, Türk kadınının kitlesel iletişim ve modern sağlık hizmetlerine erişimiyle güncellenen halk bilgisinin ritüel alanda bir geçiş dönemi ritüelinin keşfine ve performansına kapı araladığıdır. Bu nedenle sahada derleme yöntemi, gözlem ve mülakat tekniği ile Karabük ili sınırları içinde gönüllü kaynak kişilerle yüz yüze görüşmeler yaptık. Sonuç olarak kadınların menopoz alanındaki bilgilenme ve bilinçlenme sürecinde asma ağlatma ritüelini menopoz geçiş dönemine uyarladığını gördük. Uyarlanma sürecinde kadınların gençliğin sorunlarını geride bırakmak için ritüelin söz dizimi ve performansına yeni elementler eklediğini kaydettik. Sahadaki mülakatlar, ritüelin ulusal sınırların ötesine de taşındığını, diasporada da icra edildiğini göstermektedir. Araştırma, geçiş dönemi merkezli ça1ışmaların geleceği için gelenek ve ritüelin modern dünyanın yeni ihtiyaçları karşısında güncellenmesi veya yeniden keşfedilmesi açısından örnek teşkil etmektedir.

Anahtar sözcükler: folklor, kadın, geçiş dönemi ritüelleri, menopoz, kötülügüün transferi

\begin{abstract}
Human life is surrounded by periods that represent the transitions from one human state to another and the traditions that accompany these periods. Transition periods are physiological, mental, emotional and social milestones of life. Human are tent to be vulnerable, and fragile in all aspects of their existence on the verge of these transition periods. That is why they often design some traditions and rituals to get all social support and supernatural blessing that they can get. The dramatic performance of these designs in the social environment is in the nature of defining and approving the new duties and responsibilities required by the new status. In a way, the social dimension of rites of passage is also an indication that this transition took place in the presence of the witnesses and with their approval as well. Limiting the rights and responsibilities of the individual, transitional rituals may also offer privileges in particular cases. In this study, the structure and function of the making vine trees cry (tr. asma ağlatma) ritual which both is both invented and inspired from an old tradition is depicted. Considering that a third of a woman's life passes in the post-menopause phase, the making vine trees cry is a ritual invented recently as the menopause transition period. The tears of the vine tree represent the transfer of the diseases in the fragile and sensitive body of the woman entering the menopause, and all the troubles that may cause her upset in the future. In the postmenopause phase, also known as the second spring, the woman makes a ritualistic entrance to her second spring with this very ritual she performs, leaving the past behind with all its abstract and concrete wounds.
\end{abstract}

Keywords: folklore, women, rites of passages, menopause, transfer of evil 


\section{Extended summary}

Folklore is not limited with folk knowledge that had been formed in old times, but embrace new ones that invented in modern times. As people cannot put new wine in old bottles, the relatively new ones are adapted to the present by establishing a connection with the past. Knowing life is limited between birth and death, man attributes symbolic meanings to physiological, emotional and social milestones of life. Transitional rituals are social dramatic events organized to celebrate, announce and approve the transition of the individual a new social state waiting at the threshold for a certain period of time that well defined. While the social rights, expectations and responsibilities of individual who are about to go through transition are defined in the rituals, some privileges or restrictions are offered in line with age and gender.

As social contract of society, transitional rituals not only announce these new settings, but also socially define their legitimate justifications. That is why rites of passage are dramatic guides of a community's age and gender value system. Menopause, which was identified as a transitional period in the 19th century in the area of medicine, is the period that represents the transition of women's life into the post-middle age phase. Since one third of a women's life passes in the post-menopausal period, the pre-menopause stage represents the threshold of the menopausal transition period.

At the threshold, the woman is expected to be preparing for the transition with her physical, mental and social fragility, vulnerability and stress. Nevertheless culture centered studies show that culture is effective in understanding and experiencing menopause. Menopause brings privileges to women in cultures where taboos related to the menstrual cycle and gender roles associated with the fear of women regulate women's daily life and their relationship with the sacred. After menopause, women may become relatively more independent from taboos associated with menstruation in a number of areas, ranging from preparing food to worshiping.

Menopause as an invented transition period in Anatolian Turkish culture has been linked to consciousness concept that suggest women to know their bodies with its all aspects. Media has carried out informative programs where menopause is introduced as second spring of women life. Making vine trees cry is a ritual that adapted an old version of a tradition into new one to celebrate second spring of women life. Making vine trees cry ritual, which was performed for young girls in the 90 s with aesthetic concerns is performed for menopausal women in millennium.

The ritual is conducted in certain neighborhoods where working class families live and immigrated to Karabük. This is related to acculturation, ritual performance not being limited to time and space. As a matter of the fact that this ritual has been carried both to other cities of Anatolia and abroad by the women who participated to the ritual and experienced its benefits. The fact that an informant who migrated to France from original locality of the ritual makes her own vine tree cry for her fellow countrymen is also proof of this. The woman who performs the ritual is chosen in the social hierarchy not according to her age but according 
to severity of the difficulties and challenges that she had survived in life. Suffering from difficulties, which has parameters such as child, spouse, illness, poverty, and taking care of the elderly in the family, determines the hierarchical place of women in the group. Wisdom doesn't come with age" proverb is repeatedly referred by informants while explaining this arrangement.

Making vine tree cry ritual is performed by demand that a woman entered post-menopause phase asked if ritual could be performed for her. The vine tree to be cried in the ritual must be the one which is old and fruitless. This type of vine tree and woman in menopause are identified with each other in terms of fertility. The ritual is performed while sun is climbing that symbolize the connection between the sun and the woman's good fortune in the future. Since women divide their life time into two parts as before menopause and after menopause, they make vine tree cry to spend a happy, healthy, comfortable and prosperous life after menopause. Verbalism of emotions and thoughts such as "I cried a lot, you better cry for me anymore", "I had enough! I am not young enough to endure" and "you are strong, so you can bear my suffering instead of me" in the ritual represent the transfer of all troubles and bad fortune that can be faced in the future to the vine tree.

While making vine tree cry, the tears seeping from its branch are the ones that the menopausal woman hopes not to shed following the ritual. These tears are believed to be sacred that shed for the last time in this transitional phase that the menopausal woman calls the second spring. After performing ritual, women hang a clean bowl under the amputated branch to accumulate the tears which must be put to use in hair care of young female members of the group. This part of ritual has been adapted from old version of the ritual that was performed for young girls in 90s. Since tears of the vine tree are believed to be sacred anyone and anything touch it must be clean as well. That is why remains of tears must be poured out to a place where no one can step on after the ritual. The social participation of menopausal women standing near the vine tree and young female members watching from far during the ritual strengthens my belief that this very ritual will also be performed in the far future.

\section{Giriş}

İnsanın antik çağlardan günümüze ihtiyaçlarını karşılayan sistemin kültür olduğu akılda tutulduğunda, insanın bu motivasyonla geliştirdiği tüm teknikler, uygulamalar, inançlar vb. halk bilgisi [folklor] içinde saklanır; yine ihtiyaçlar dahilinde güncellenerek nesillere nakledilir. Bu çerçevede "folklor, halkın antik uygulamalarının güncel formları ve bunların yanı sıra oluşan popüler yeni formlarıdır" (Thompson, 1846: 862) tanımı günümüzde de geçerlidir. İnsan, kendisine nakledilen halk bilgisini özgün haliyle takip etmese de kökeni ve meşruiyeti itibariyle atalarıyla ilişkilendirdiği güncel formlara itibar etmeye devam eder. Kültürleşme süreçlerinin hızı ve yoğunluğu paralelinde yapı değişirken, işlev korunur. Bu çerçeve içinde folklor, "bir grup insanın ait oldukları alt kültürlerden üst kültürle çevrelenmiş yeni yaşam alanlarına taşıdıkları, alışkanlıklarındaki gibi içgüdüsel bir motivasyonla uygulamaya, yaşatmaya devam ettiği gelenekler, süreçler, dünya görüşüdür” (Tylor, 1891a: 16). Bu, 
grupların kendilerini grup olarak tanımlamalarını mümkün kılan kültür elementlerinin doğal habitatlarında olduğu gibi sıkı takibine (Tylor, 1891b: 539) imkân tanır. Bu bağlamda folklor, grupların şehir hayatı içinde yaşatmaya devam ettiği kültür elementleri, arkaik düşünce, inanış, uygulamaların mevcut yaşam koşullarına uyarlanmış halidir. Şehir hayatına taşınan halk bilgisi gecekondu mahallelerinde, tekstil atölyelerinde, barolarda, ağır sanayi bölgelerinde kendisine, geçmişle bugünü kaynaştıran bir yol bularak yaşamaya, yaşatılmaya ve aktarılmaya devam eder. Bu nedenle olsa gerek, folklorcuyu şehirde halk bilgisi araştırmaya davet edenler şöyle bir not düşer: "Şehirdeki halkın folklorunu çalışmaya kaç ömür gerekir?" (Dorson, 1970: 216).

İnsan, yaşamının doğum ve ölüm arasındaki zamanla sınırlı olduğunu bilerek yaşayan tek canlıdır ve hayatın fizyolojik, zihinsel, duygusal ve sosyal dönüm noktaları belirli sosyal olaylar eşliğinde deneyimler. Geçiş dönemi ritüelleri olarak adlandırılan bu sosyal olaylar, bireyin içinden geçtiği geçiş döneminin sunduğu yeni sosyal statünün, bu statünün gerektirdiği sorumlulukların ve yetkilerin toplum tarafindan kutsal veya seküler bir düzen içinde onaylanmasıdır. "Kutsal ve seküler arasında öyle bir uyuşmazlık vardır ki, kimse birinden diğerine eşikte bir süre beklemeden geçiş yapamaz” (Van Gennep, 1969; 1). Sosyal statüsü ve rollerin göstergesi olarak geçiş dönemi ritüellerinin toplumsal alanda icrası, olayın tanıklık gerektirmesindendir.

Erginlenme geçiş dönemleri bireye sorumluklar, yetkiler yüklemekle kalmaz; kimi hallerde de kısıtlamalar getirir. "Yaşın belli aşamalarının net biçimde ayrılması arkaik kültürlerden modern kültürlere kadar her yerde olağandır” (Malinowski, 1992b: 81). Erginlenme ritüelleri, sosyal yapıda meydana gelen görev ve sorumluluk değişikliklerini duyurmak, onaylamakla kalmaz; sosyal yapıdaki dönüşümün meşru gerekçelerini de sunar. "Ritüel, sosyal sözleşmenin somutlaştırılmasıdır. Bu yüzden söz ve eylemden oluşur” (Rappaport, 1992: 255). Bireyin fizyolojik erginlenmesinin ritüelle toplumsal düzeyde onaylanması bir yönüyle de, onu statüler açısından yeni bir kategori içinde konumlandırmakta, bir sonraki erginlenmesine kadar bu kategori içinde sosyal olarak tanımlamaktadır.

\section{Metodoloji}

Geçiş dönemlerine eşlik eden ritüeller, bir topluluğun yaş ve cinsiyetle ilgili değerlerinin dramatik kılavuzlarıdır. Kültürlerarası alanda yaş ve cinsiyetle ilişkilendirilen ritüeller, grubun aktif üyesi olarak bireyin mensubu olduğu kültür çevresindeki konumunu tanımlar. Onu sosyal olarak belirli kategoriler içine yerleştirirken; ritüelle sorumluluklarını, haklarını, ayrıcalıklarını ve ritüelin gerektirdiği sosyal kısıtlamaları informel yollardan bireye belletir. Bu bağlamda, geçiş dönemi ritüelleri folklor disiplini açısından yaş, cinsiyet, statü kavramları çevresinde ortak inançları ve değer yargılarını paylaşan akran ve/veya hemcinslerin deneyimlediği sözlü, dramatik sosyal olaylardır.

Doğum, evlenme, ölüm vb ile sınırlı olmayan bu alanda derlemenin mekânı da son derece geniştir. Zira, "folkloru derlemek için çantanı toplayıp egzotik bir yere gitmek zorunda değilsin. Aradığın folklor işyerinden, annenin mutfağından, kız kardeşinin oynadığı park- 
tan, arkadaş toplantılarından veya kendi hatıralarından uzakta değildir" (Wilson, 1986: 227). Geçiş dönemi ritüelleri, gruba özgün olabileceği gibi, kültürleşme sürecinde grubun diğer gruplarla teması sırasında da öğrenilebilir. Zaman içinde kültürün özgün bileşeni gibi yorumlanıp, kaynağı unutulabilir. "Geleneksel toplumlarda bile hayat değiş̧ir, bu yüzden gelenek de değişir” (Hobsbawn, 2009: 3).

Araştırmaya konu olan menopoz geçiş dönemi ritüeli, asma ağlatma, Karabük Fevzi Çakmak, mahallesinde yaşları otuz iki ile seksen üç arasında değişen kadınlar arasında katılarak gözlem yöntemiyle kaydedilmiştir. Bu mahallelerde haneler Karabüklü, Kastamonulu, Trabzonlu esnaf ve işçi ailelerin özel mülkiyetindeki bahçeli müstakil evlerden müteşekkildir. Mahalle sakinleri ev sahipleri ve kiracılar olarak biz ve ötekiler arasındaki sınırları tayin etmektedir. Bahçeleri bitişik sıralı evler şeklinde araziye dağılmış mahallede komşuluk ilişkileri yakındır. Kadınlar kendi aralarında kızlar ve gelinler olarak ikiye ayrılmakta; mahalleye dışardan gelenler gelin, mahallenin içine gelin olanlar kız olarak adlandırılmaktadır. Mekânsal yakınlık grup oluşumunun temel dinamiklerinden biridir. Komşuluk grup oluşumunu, hizmet değiş tokuşunu, işbirliğini mümkün kılar. "Grubun temel dinamiği mekânsal yakınlıktır. İnsanlar ancak birbirinin menzili içindeyken birlikte çalışabilir, beceri ve iş bakımindan birbirlerini tamamlayabilirler" (Malinowski, 1992b: 80).

Geleneğin zemini bu mahallelerle sınırlı olsa da buradan başka alt kültürlere göç eden kadınların geleneği yanlarında taşıdığı derlemeler sırasında anlaşılmıştır. Fransa'ya evlenerek göç eden B. Demir (2021) menopoza giren hemşerileri için bu geleneği diasporada icra etmektedir. Bu da ritüelin zaman ve mekânla sınırlandırılamamasındandır. "Ritüelin etkisi icra anıyla sınırlandırılamaz. Bilindik zaman ve mekânlarda icra eğilimi gösterse de zaman ve uzam bakımından sınırları aşabilir" (Connerton, 1999: 71). Derlemeler sırasında mülakatlar yüz yüze canlı ortamda yapılmış, görüşmelerin sesli ve görsel kayıtları alınmıştır. Asma ağlatma ritüeli, Mart ayının son haftası ve/veya Nisan ayının ilk yarısında talep üzerine icra edilmektedir. Asmalar belirli hanelerce ağlatılmaktadır. Asması ağlatılacak kadın, hane sahiplerine durumunu bildirmekte, böylece kendisi için asma ağlatılmasını talep etmektedir.

Araştırmaya gönüllü olarak katılan kadınlarla derleme yaparken yönlendirilmemiş görüşme tekniği kullanılmıştır. Bu yöntem kaynak kişinin bir konuda neredeyse tamamen serbest ve genel mahiyette konuşmasını, araştırmacıya "kaynak kişiyi hazırlıksız ve ayrıntılı cevaplar vermeye teşvikle, çeşitli konularda geniş bilgi” (Goldstein, 1983: 75) sağlamaktadır. Asma ağlatan hane sahiplerine kaynak kişi S. Taşkıran vesilesiyle erişilmiş, gönüllülük esaslı katılım sağlanmıştır. Kaynak kişilerin ritüele dair bilgisi cinsellik, suç, din vb. konular içermediğinden kaynak kişi aksi yönde talepte bulunmadıkça isimleri olduğu haliyle metin içinde verilmiştir. Araştırma sırasında ve sonrasında "materyalin anonimliği, kaynak kişinin güven ortamından emin olmak, kaynak kişilerden onay alınması ve mahremiyete hürmet" (Carter, 2005: 152) ilkelerine riayet edilmiştir. Folklorcunun derlemeleri, gözlemleri sırasında kaydettiği duyguları yazıya dökmesi, deneyimlendiği haliyle aktarması neredeyse imkânsızdır. Nitekim bu çalışmada da ritüel sırasında gözlemlediğim duyguları ancak elimden geldiğince aktarabilmekteyim. 


\section{Bir geçiş dönemi olarak menopoz ve kültür: "Kadın var, kadın var!"}

Menopoz, kadın hayatının orta yaşlarına denk düşen, yeni bir evreye geçişini temsil eden fizyolojik süreçtir. "Menopoz adet döngüsünün sona ermesi, kadının psikolojik veya patolojik nedenlere bağlı olmayan on iki ay aralıksız adet görmemesiyle bu evreye normal şartlar altında girilmiş sayılır” (WHO, 2021). Bio-medikal literatürde de pre-menopoz, menopoz ve post-menopoz şeklinde üç aşamada tecrübe edilen bu süreç geçiş (transition) şeklinde adlandırılmaktadır. Kadının doğurganlığının normal koşullar altında sona erişini temsil eden bu evrede, kadınların menopozu nasıl deneyimledikleri kültürden kültüre farklılık göstermektedir. "Biyolojik değişimler aynıyken, kadının menopoz sonrası kazandığı kimlik, statü, prestij gibi sosyal etkenler kadının menopozu nasıl deneyimlediğinde belirleyicidir" (Zeserson, 2001: 182). Üstelik kültürlerarası alanda menopoz ve semptomlarını tarif etmek için kullanılagelen veya icat edilen kelimeler, gelenekler, ritüeller de menopozun halk arasında nasıl anlamlandırıldı̆̆ını göstermektedir.

Kültürler arası alanda menopozun kendisi de semptomları da kültürün değerler sistemi dahilinde anlamlandırılmaktadır. Bu bağlamda Hindistanlı kadınların bu geçişi sabırsızlıkla beklediği; Japoncada menopoza dair kavramların Batı dillerinden uyarlandığı; Aborjin kadınlarının dönemi biyolojik olarak algılamadığı, kültürel olarak deneyimlediği; Arap kadınların menopozu dermansız bir hastalık olarak gördüğü kaydedilmektedir (Jones vd., 2012: 7; Jassim ve Al-Shboul, 2008: 359; Sing ve Arora, 2005: 180 ; Zeserson, 2001: 190). Kültürler arası alanda menopozun biyolojik anlamda da farklı deneyimlenmesini kültürle açıklayan çalışmalar "kültürün halk inançları, halk sağlı̆̆ı, toplumsal cinsiyet rollerine bağlı beklentileri, dil, beslenme, din, ekonomi ve eğitim kurumları içindeki sosyal normlar çevresinde açıklamaktadır” (Melby vd. 2005: 497). Anadolu'da gençlik ateşi, ikinci bahar, günden kalmak, günden kesilmek, adetten kesilmek şeklinde adlandırılan menopoz geçiş dönemine dair semptomlar da ateş basması, ateşlenme, gençleşme, ağlaklık², ufalma ${ }^{3}$, soğuk basması, Azrail üfürtüsü gibi kelimelerle tanımlanır.

Adetin, kirlenmeyle ilişkilendirildiği ve tabularla çevrelendiği kültürlerde ${ }^{4}$ menopoz yeni bir başlangıca işaret eder. "Kirleten her zaman haksızdır. Yanlış duruma düşmüş, geçilmemesi gereken bir sınırı geçmiştir. Bu geçiş de başka birini tehlikeye sokar" (Douglas, 1984: 140). Post-menopoz evresinde kadının kandan azat oluşuna eşlik eden ritüellerin, menstrüasyona eşlik edenler kadar gelenekselleşmediği görülmektedir. Nitekim, "toplumlar pragmatiktir ve en gözde formların gelenekselleşmesine yatırım yapar. Öyle ki, bu geleneksel biçimlere düzmece bir bağlılıkla sadakat gösterilir" (Benedict, 2003: 53). Menstrüasyona eşlik eden uygulamalar kadını, sosyal sınıflandırma içinde genç ve yaşlı arasında bir eşikte konumlandırırken; ona toplumun niceliğine katkıda bulunmak üzere sorumluluklar da tanımlamaktadır. "Genç bir kızın ilk kanaması, onu evlenilebilirliğinin göstergesidir" (Kapchan, 1995: 9). Bu bağlamda kadının kirli olarak kabul edilen bir sıvıdan daimi olarak ayrılışını temsilen menopoz, temiz bir alanla birleşmeye de işaret etmektedir. "Bedenin deliklerinden çıkan maddeler marjinaldir. Tükürük, kan, süt, idrar, ter, gözyaşı ve dışkı dışarı çıkarak be- 
denin sınırlarına karşı gelir” (Douglas, 1984: 122). Menopoza girmiş kadınların Anadolu sahasında mezhepler çevresinde az çok değişmekle beraber ibadethanelere girip çıkmak, erkeklerden kaçma (kaç göç ve sakal kesme gelenekleri), örtünme vb. alanlarda tabi oldukları kısıtlamalardan muaf tutulduğu kaydedilmektedir (Erdentuğ, 1959: 39).

Menopoz, kültür alanında yeni tartışılmaya başlanan bir geçiş dönemidir. Ne var ki, doğurganlığın sonlanması ve adet kanaması çevresinde kadının tabi olduğu kısıtlamaların sona ermesiyle ilişkilendirilen bir geçiş dönemi olarak halk bilgisi alanında bu döneme dair bir farkındalığın olduğu, dönemi tasvir eden halk kavramlarından ve terimlerinden de anlaşılmaktadır. M. Boz’un (d. 1942) şu sözleri bu bağlamda kayda değerdir:

"Bizim gençliğimizde menopoz diye bir şey yoktu. Adetten kesilir, günden kalırdık. Bundan sonra üstün kirlenmez ${ }^{5}$, çocuğa da kalmazsın. Bu kadardı. Şimdi doktoru, hemşiresi, ilacı. Bizimkisi daha kolaydı. Bilmediğimizden ateş basıyor, Azrail üfürüyor der geçerdik. Yataklara da düşmezdik. Nasıl düşeceksin, damda beş baş, evde bilmem kaç boğaz. Bilmediğimizden 'günden kaldık', dedik geçtik."

Halk arasında menopoz yerine kullanılan bir diğer isimlendirme olan gençlik hastalığı da bir yönüyle duygusal ve fiziksel değişime işaret etmektedir. Mülakatlarımız, pre-menopoz evresindeki kadınların, ilk erginlenme yıllarındaki kanama sıklığı, enerji kapasitesi, duygu durum değişiklikleri bakımından menopozun ergenlik döneminin orta yaşlarda tekrardan ve son bir kez tecrübe edilmesi şeklinde yorumlandığını göstermektedir:

"On üç yaşımdan bu yaşıma kadar gün görüyorum. O zaman çocuktum. Anlayamadım. Şimdi şu aklımla bunu bir nimet olduğunu fark ederek yaşıyorum. O kalp çarpıntıları, gidişli gelişli haller, ayaklanmalar, kıpırtılar yıllardır bilmediğim şeylerdi. Son bir kez bunları yaşamak, gençliğimden bir zamanı çalmak gibi. Bu yönleriyle gençlik; terleme, ateş basması gibi yanlarıyla da hastalık işte... Hem gençlik hem hastalık...” (Başkurt, 2021).

Kaynak kişinin referansta bulunduğu bu duygu halleri menopozun kültürler arası yaygın bir şekilde kabul gören semptomları arasında yer almaktadır. Pre-menopoz evresi ile genç kızlığın ilk evreleri arasındaki duygusal ve fiziksel deneyimin paralelliği, orta yaş kadınlar arasında benzer bir şekilde dile getirilmektedir. Geçiş döneminin fiziksel anlamda dış dünyaca algılanması, kandan öte başkaca göstergeler üzerinden yapılmaktadır. "Genç kızlığa geçişin kandan başkaca göstergeleri vardır. Geçiş döneminin tarihlendirilmesi de aslında bu göstergelerden hareketle yapılır" (Van Gennep, 1969: 65). Literatür bu evrede ergenliği bilinçsizce deneyimleyen kadınların, menopoza daha derinlemesine odaklandığını kaydetmektedir (Dillaway, 2005: 409-410). Her ne kadar halk arasında menopoz yerine kullanılan adlandırmalar, ani, keskin bir geçiş dönemine gönderme yapsa da semptom adlandırmaları bu geçişin öncesine dair farkındalığa işaret etmektedir. Türk modern tıp alanında yakın zamanlara kadar sağaltma ve menopoz ilişkisine dair tartışmalar olmadığı gibi; halk arasında da sürecin tıp ilmiyle ilişkisine dair farkındalığın bilinç düzeyinde olmadığı kaydedilmektedir. Halkın kendisi kadar hekimlerin de böyle bir yaklaşım sergilediği, M. Erol (2009: 369, 375) tarafından da gözlemlenmiştir. Günümüzde de ise kadınlara menopoz geçiş dönemine dair farkındalık kazandırmak ve konuyla ilgili bilinç oluşturmak için kurumsal düzeyde girişimler yapılmakta, menopozlu kadının süreçteki fiziksel, ruhsal ve sosyal deneyimi kayıt ve kontrol 
altına alınmaktadır. Adet düzensizliği şikayetiyle hekime başvuran G. Kurt'un (2021) kendisine menopoz teşhisi konana kadar içinden geçtiği sürece dair farkındalığı yoktur. Kendisine semptomlar söylendikten sonra semptomlara karşı geliştirdiği duyarlılığı şu sözlerle anlatmaktadır: "Kızımın çocuklarına bakıyorum. Sıcaklayınca çocukları soydum, üşüdükçe kat kat giydirdim. Meğer yanan da üşüyen de benmişim. Doktor bir bir anlatınca anladım da etrafımdakilere sormaya başladım sıcak mı soğuk mu diye!” (Altındal, 2021). Böylece geçmişte kendiliğinden, doğal ve kültürel olarak deneyimlenen bu geçiş dönemi bugün hekimler nezaretinde kontrollü bir şekilde gerçekleşmektedir.

\section{Ritüel ve asmaları ağlatan kadınlar: "Kadınım asma!"}

Geçiş dönemi ritüelleri bireyin, sınırları iyi tanımlanmış bir pozisyondan eşit derecede tanımlanmış başka bir pozisyona geçişini mümkün kılan sosyal olaylardır (Van Gennep, 1969: 3). Ritüel sosyal yanıyla ona eşlik eden dil, sembol ve simgelerden oluşur. "Ritüel bağlamı yönünden sembolün kendisinden çok sembole karşı katılımcıların geliştirdiği tutum ön plandadır” (Fogelin, 2007: 59). Tümüyle sözsüz bir ritüelde bile, eylem, ritüelde kullanılan araç gereçlerin, jest ve mimiklerin sembolik anlamıyla mesaj içerir. "Ritüel çok sayıda türün üyelerinin kendilerinden olanlarla iletişim kurduğu kalıplaşmış gösterilerdir. İnsana özgü yanı, dilin simgesel ve sembolik boyutudur" (Rappaport, 1992: 249).

Her gelenek zamanın bir noktasında tekrarlanarak ritüele dönüşme kapasitesini haizdir. S. F. Nadel'in (1954: 99) sözleriyle "gelenek irrasyonel, mistik, doğaüstü karakterler taşıdığındaysa dini ritüel boyutuna ulaşır”. Bu noktada dini ve seküler ritüel ayrımına gidilmelidir. Ör-

neğin M. Wilson (1957: 9) dini eylemi ritüel; pragmatik, dünyevi ve geleneksel olan kapsamlı planlanmış dramatik olayları seremoni veya seküler ritüel olarak adlandırmaktadır. J. Goody'de (2010: 36) ise böyle bir ayrımın modern dünyada güç olduğu; pragmatik bir sonuca götüren vasıtalarla nihai fayda arasında irrasyonel bağ olan standartlaşmış eylemler ritüel şeklinde tanımlanır. Seküler olanlarda bile doğrudan doğaüstüyle ilişkilendirilemese de örtülü işlev yüzünden ritüelin sekülerliği gizli kalır. Bir başka kaynakta (Bell, 1997) böyle bir ayrımın formalizm, geleneksellik, değişmezlik, kurallılık, kutsal sembolizm ve performans üzerinden sistematize edildiği görülmektedir. Ritüel ve seremoni ayrımının en keskin görüldüğü alan eylemin işlevidir. "Ritüel dönüştürücü, seremoni onaylayıcıdır" (Turner, 1991: 65). Bu bağlamda geçiş dönemlerinde fiziksel ve ruhsal dönüşümün yanı sıra bir statüden başka bir statüye de geçiş olduğu düşünüldüğünde asma ağlatma ritüelinin dönüştürücü işlevi ön plandadır. "Grup oluşumunun ilkelerinden biri de insan fizyolojisine ve beden yapısına bağlıdır. Doğuştan özellikleri ve hastalıklarıyla cinsiyete göre örgütlenme çoğunlukla yaş derecelerine bağlıdır. Bu fenomen en ilkel olandan en çağdaşına her yerde olağandır” (Malinowski, 1992: 81).

Örtük işlevi, kadını yeni bir kadınlık haliyle bütünleştirmek; bu yeni haliyle topluma takdim ederek onu yeniden yapılandırmaktır. Açık işlevi ise toplumsal cinsiyet rolleri üzerinden adetle ilgili tabulara tabiiyet bakımından kadını rahatlatmaktır. "Ritüeller insanları tehlikeli suların diğer tarafına taşıyan güvenilir köprülerdir” (Schechner, 2015: 263). Freud'un sözleriyle ritüel duyguları sağaltır, endişe, korku, kötü şans karşısında toplumu korur. Bununla 
birlikte bir diğer açık işlevi de kadının içinden geçtiği doğal süreci bir geçiş dönemi ritüeliyle normalleştirerek, topluluğun diğer kadın üyelerinin de geçiş dönemine dair endişelerini gidermektedir. "Ritüelde bireysel ve kolektif endişeler, korkular yineleme, mübalağa, yoğunlaşma, basitleştirme gibi yöntemlerle beyne endorfin salgılaması için uyararak dindirilir" (Schechner, 2015: 264). Tüm geçiş dönemleri özelinde bireyin kırılgan ve savunmasız olduğu gerçekliğinden hareketle, asma ağlatmak "kötülükleri uzaklaştırırken, doğa üstü alanla dünyevi alanı da uzlaştırmanın bir yoludur” (Turner, 1991: 32).

Asma ağlatmak, post-menopoz evresindeki bir kadının talebi üzerine belirli hanelerce icra edilmektedir. Ritüeli icra eden kadın yaşta değil, çilede üstün olan bir kadın olarak karşımıza çıkmaktadır. Eşinden, çocuklarından, yoksulluktan, aile sorunlarından ve hastalıklardan çile çeken kadınlar arasında en kıdemli olana asmayı ağlatma vazifesi verilmektedir. Asma ağlatma geleneğinin beş on yıl önceki bağlamıyla bugünkü bağlamının birbirinden tümüyle farklı olduğu görülmektedir. Geçmişte asma, genç kızların ve kadınların saçlarının güzelleşmesi, gürleşmesi için ağlatılmaktayken; bugün bu bağlama menopozlu kadınların çilelerinin transferi işlevi de eklenmektedir. Bu yünüyle işlev açısından icat edilmiş gelenek özelliğindedir.

İcat edilmiş gelenekler geçmişlerini oluşturarak şimdiki zamanda karşılığını bulan, yeni durumlara uyarlanmış, eski durumları akla getiren formlara bürünmüş, tekrarla değer ve normların eklenmesiyle oluşmuş pratiklerdir (Hobsbawn, 2009: 1-3). Geleneğin zemininde asma ağlatmanın 90’lı yıllardaki bağlamı S. Berberoğlu (2021a) tarafından şu sözlerle anlatılmaktadır:

“1979 doğumluyum. İlkokuldayken asma ağlatılacak derlerdi. Biz okuldan gelince asmanın ağlatıldığı eve giderdik. O zaman da abdest alır, iki rekat namaz kılardık. Bugünkü gibi asmayla konuşur, gönlünü alır, sonra ağlatırlardı. Yine bugünkü gibi yaşlı kadınlar yapardı, ama değişikti. Asma ağlamaya başlayınca biz de ağlardık. Ağlamamız söylenirdi, ağlayamayanlara da kızarlardı. O gün elimizde kaplarla gelip göz yaşını alır, evimize götürürdük. Saçlarımızı yıkarlardı. Saçkıran olan kızların bile saçı çıkardı. Benim de saçımı bir yıl ben uyurken keçi yemiş. Uyanınca bir baktık saçımı ordan burdan yemiş. Benim de başımı yıkadılar. Dört beş aya saçım çıktı. Kızlarıma da şimdi ben yapiyorum".

Ritüel ve mit arasında da bağ kurulmaktadır. Zamanın bir noktasında mit olan bir anlatıdan, önce efsaneye ardından rivayete tekamül edilen, yazılı tarihle açıklanması imkansız sanal bir gerçekliğin asmanın gözyaşının tanımlanmasında etkili olduğu görülmektedir. "Ritüeller sabit fikirlerin güvenli kasaları değil, yeni malzemeler üreten, geleneksel formları yeni biçimlerde tekrar bir araya getiren dinamik eylemsel sistemlerdir" (Schechner, 2015: 258). Bu yönüyle asmanın göz yaşının Hz. Ali’nin göz yaşı olarak tanımlandığı görülmektedir. Tam da bu nedenle asmanın göz yaşının kirletilmemesi için azami özen gösterilmekte, asmaya abdestsiz yaklaşılmamaktadır. Asmanın göz yaşıyla saçlar, bir leğen içinde yıkanmakta, artan göz yaşı ise ayak değmeyecek bir yere dökülerek toprakla buluşturulmaktadır. "Ritüellerde simgesel mitler görülür. Ritüellerde eylemler çoğunlukla mitoslar denilen gelişmiş aracılar kanalıyla dile getirilen kültürel değerlerin bir örneğidir” (Connerton, 1999: 85). 
İcat edilmiş gelenekte ise asma, post-menopoz evresindeki bir kadın için ağlatılmaktadır. Ritüel, geleneğin zemininde olduğu gibi günümüzde de güneş yükselirken icra edilmektedir. Orta yaşlı kadınların yakından, gençlerin uzaktan katıldıkları bu ritüelde çilede üstün, halihazırda post-menopoz evresinde olan bir kadın asmayla konuşmakta, onun gönlünü almaktadır. Ardından da temiz bir bıçakla asmanın sağlam gövdesine bir-iki santimetre derinliğinde bir kesi açarak ritüeli tamamlamaktadır. Kesilen bölgenin altına temiz bir kap iplerle bağlanmakta; asmanın göz yaşı, üç beş gün bu kaba akıtılmaktadır. Gözyaşı tükendiğinde de asmanın yarası kapatılmaktadır. Asmanın yarası kendi toprağından yapılan çamurla kapatıldıktan sonra, temiz bir bezle sarılmaktadır. Ağlatılacak asmanın özellikleri ise S. Başdemir (2021) tarafından şu sözlerle anlatılmaktadır: "Asma yıllanmış, yaşlı olacak. Meyveden kesilmiş, yaprağa durmuş olacak. Huzurlu bir çatının altında olacak. Her evde sıkıntı, dert olur ama ev huzursuzluğu başkadır. Böyle bir çatının altındaki asmadan hayır gelmez". Ağlatılan asmanın meyveden kesilmiş olması ile menopozlu kadının fiziksel durumu arasında benzerlik kurulmaktadır. Bu bağlamda asmanın yaprakları, kadının çocukları, torunları, yeğenleri gibi tasavvur edilirken; asmanın meyveden kesilmiş olmasıyla kadının doğurganlığının sonlanması arasında paralellik kurulmaktadır.

Asma ağlatma ritüelinin doğa üstü alanla bağı, dua üzerinden kurulmaktadır. Bununla birlikte ritüel Perşembe ${ }^{6}$ günü icra edilmektedir. Ritüelin güneş yükselirken yapılması da dikkate değerdir. İkindi ezanından önce tamamlanması gereken ritüelde, güneşin yükselmesiyle kadının sosyal statüsünün yükselmesi arasında düşünsel bir bağ vardır. Ritüel sırasında örtünme kuralına da dikkat ediliyor olması, ritüelin İslâm dini çerçevesinde doğa üstü alanla kurulan bağın samimiyetini simgelemesi açısından değerlidir. "Ritüeller onları icra edenlerce kayıtsız şartsız uyma biçiminde olmasa bile, uyulması gereken şeyler olarak algılanır ve ritüel değeri olan eyleme, engel olmak her zaman kırıcı olarak tanımlanır" (Connerton, 1999: 71).

Bu ritüelde duanın sözleri içinde İslam ve Şamanizm'e dair unsurların içtenlikle ve kendiliğinden kullanıldığı görülür. Asmayı ağlatan, asmayla canlı bir varlıkla konuşur gibi konuşmakta; dertleşmekte; izin almakta; asmadan özür dilemektedir. "Dua inancın ve ritüelin doğal paylaşanıdır. Dua ederken iman sahibi aynı anda, bir amaç için düşünürken, dili de bir vasıta olarak kullanır" (Mauss, 2008: 23). Dua burada menopoza karşı kolektif ve olumlu bir enerji üretilmesinde de rol oynamaktadır. Ritüele duanın eşlik etmesinin sosyal nedenlerinden biri de bu enerjiye duyulan ihtiyaç olmalıdır. "Ritüelde icracı halihazırda bilinen bir dili, olayları, kolektif formları, değerleri ön plana çıarırken; eylemin dinamiklerini, yaratıcı bir enerjiyi de ortaya çıkarır" (Abrahams, 1977: 106). Duanın sözleri şöyledir:

"Kız Asma, gelin Asma, kadınım Asma! Ben seni kesmezdim. Sen şimdi ağ-larsan bizim gözümüzdeki yaşı sen alırsın. Sana ahrette hesap yoktur. Biz hem burda hem de ahrette sıkıntı var. Senin çilenin hepsi burda, bizden öncekileri gördün, bizden sonrakileri de görürsün. Asma, biz ağlamaya doyduk. Bundan sonra sen ağla. Sen gibi gün görelim, senin gibi kökleşelim, dallanıp, budak-lanalım. Bismillah...” 
Dua sözlerinde biz dilinin kullanılması, yakarma, özür dileme, açıklamaların yapılmas1 ritüel eylemin söylemindeki tutumu ele vermektedir. Nitekim "lanetleme, kutsama, ant içme, sormak, yakarmak, açıklamak, şükretmek, boyun eğmek, saygı, borçluluk ve pişmanlık duyguları ritüel dilin eylem üzerine sözlü ortak eylemsel tutuma işaret eder" (Connerton, 1999: 91-93). Böylece ritüeli icra eden kendi hitabet gücünü kullanarak aslında icrada hazır bulunanların tümü adına konuşmakta, kolektif duygu, dilek ve tutuma da lisan olmaktadır. Radcliffe-Brown, inanç ve ritüel üzerinden kolektif duygulara yaklaşırken, ritüelin belirli duygulara vurgu yaparak sosyal yaşamın sürdürülebilirliğine katkı sağladığını söyler. Bu bağlamda ritüele katılan birey aslında doğal olarak duygudaşlık geliştiremese de ritüeldeki kolektif duygunun paylaşanı haline gelir (1945: 34-35).

İcracının hitabet yeteneğine bağlı olarak söz dizimi yıldan yıla değişebilmektedir. Bu da ritüelin sözlü kültürle bağıyla ilgilidir. Form ve sözler sözlü kültürde tanıklık vasıtasıyla öğrenilip, tekrarlandığından bu, ritüelin yapısındaki değişimi de yavaşlatır. "Ritüelin dizgisel formunun ve söyleminin tekrarı icrasındaki kusurların tolere edilmesini sağlar. Ne kadar kusursuzca icra edilirse edilsin, icrada varyasyonlar gerçekleşir. Yine de söylemin mesaj1 ritüele katılanlarca bağlamı içinde alınır” (Rappaport, 1992: 250). Örneğin 2020 yılında asmayı ağlatan M. Köse (2020) asmaya hitap ederken kendi başından geçenleri anlatmaktadır. Ardından Asma'dan "kusura bakma, ahrette yakama yapışma, ben usandım başımdan. Benim yerime sen ağla!” diyerek asmayla dertleşmekte; ardından gönlünü almakta; ve nihayet asmayı ağlatmak için bıçağı asmanın gövdesine vurmaktadır. Asma'yı bir isim gibi söyleyen, canlı bir varlık gibi muhatap alan asmaları ağlatan kadınlar örneğinde asma, ağaç kültürünün Şamanizm ve İslam dinlerinin sözlü kültür alanındaki senkretik bir örneğidir. Bu da ritüel mesajının anlam ve bağlam bakımından dini değişim süreçlerine dayanıklılığından ileri gelmektedir. Öyle ki "Ritüel uzun yıllar aynı kalsa dahi, tasarım ve icra sırasında dini mesaj ve inançlar değişebilir. Değişmeyen deneyimsel açıları ve katılımcıların sosyal ilişkilerine katkısıdır" (Fogelin, 2007: 58).

Asma ağlatma geleneğiyle pre-menopoz evresini şu veya bu şekilde tamamlayarak menopoza tümüyle girmiş kadının geçiş dönemi topluluğun kadın üyelerinin tanıklığında gerçekleşmektedir. "Adet gören kadınlar tehlikenin; post-menopoz evresindeki kadınlar ve atalar, saygının odağıdır” (Balzer, 1981: 856). Böylece menopozlu kadının tabular alanında o güne kadar tabi olduğu kimi kısıtlamalardan da azat oluşu grup üyelerince onaylanmaktadır. "Ritüel, katılımcıların dikkatini özel bir anlam taşıyan düşünceye ve duyguya sevk ederken, simgesel nitelikli kuralları da ön plana çıkarır" (Lukes, 1975: 291). Nitekim, menopozlu kadın artık kimse için tehdit ve risk oluşturmayan manevi anlamda temiz bir kadın olarak yeniden tanımlanmaktadır:

"Sıralı oruç tutabilirsin, namaz kılabilirsin, borçsuz ibadet edebilirsin. İstediğin zaman türbe gezebilirsin. Camiye gidebilirsin. Kitaba yanaşabilirsin, çoluğunu çocuğu-nu okuyabilirsin, mezara gidebilirsin. Dul bile olsan erkek olan eve rahat girer çıkarsın. Kimse senden kötülük ummaz. En basitinden, biri doğum yapsa onun yanına bile kork-madan girebilirsin. Ben üstüm kirliyken, "birinin çocuğuna nazar değecek de benden bilecekler" diye kimsenin evine girip çıkmazdım. Üstün kirliyken yemişli ağaca bile çıkamazsın. Yere düşen yemişten yersin. Bunların hepsi bitiyor. 
Bir kocanla arandaki iş kalıyor. Ona da yıkanırsın, tertemiz olursun” (Başdemir, 2021).

Türk-İslam medeniyet dairesinde menopozlu kadınların tabular açısından durumunu belirleyen kimi kaidelerin nispeten esnek olduğu kaydedilmektedir. Bu açıdan menopozlu kadının, erkekle statü bakımından kimi alanlarda eşit haklara sahip olduğu göze çarpmaktadır?. Ritüelin icrasını takiben, asması ağlatılan kadın tarafından yemek verilmektedir. "Sosyal yeme-içme birleşme ritüelidir. Duygu bağının onayıdır. Armağan kategorisi içinde değerlendirilmelidir. Bir olmanın, biz olmanın yeme-içmeyle gösterilmesidir" (Van Gennep, 1969: 29). Ritüel yapısı bakımından armağan kategorisinde değerlendirilebilecek bu yemek ikramı, ritüel sonrası grup içi dayanışmanın ve duygudaşlığın pekiştirilmesi işlevini karşılamaktadır.

\section{Kötülüğün ve kara bahtın asma'ya transferi: "Sen ağla asma sen ağla!"}

Kötülüğün canlı varlıklara veya nesnelere aktarılabileceği düşüncesi arkaik insandan modern insana intikal etmektedir. Hastalıklar, musibetler, belalar, kazalar, suçlar, sahibinden bir başka varlığa inançlar alanında ve/veya gönüllülük esasına dayalı olarak aktarılabilmektedir. Frazer'ın (1913: 1-2) fiziksel olanla düşünsel olanın birbirine karıştırılması şeklinde tarif ettiği kötülüğün transferi (transfer of evil), insanın taşımak istemediği bir sıkıntıyı başka bir varlığa veya nesneye aktarmak için keşfettiği, geliştirdiği yol, inanç ve yöntemleri kapsar.

Anadolu folkloru alanında ise bu türden pratikler, hastalığı başkasına savma; hastalığı satma ve/veya giydirme şeklinde adlandırılmaktadır. Özellikle hastalıkların ve musibetin hayvan ve bitkilere aktarılması anlamında geçiş dönemi ve halk hekimliği alanında uygulanmaktadır (Koşay, 1939: 67; Ülkütaşır, 1974: 51). Gelişimi geri olan çocukların delikli kayalardan geçirilmesi (Petekçi, 1962: 2743); hastaların eşyalarının ağaç kovuklarına konulması (Evren, 1952: 477); Cin çarptığına inanılan "tıpkılı, tıgalı, tebeli" çocuklardaki anomalileri yaşayan başka bir varlığa geçirmek için lohusanın çocuğunu emzirmeden evvel bir köpeği emzirmesi; çocuk düşüren kadınların hamaylı içine konan canlı bir kertenkeleyi boyunlarında taşıması bu türden bir uygulamalardır. Başka bir örnekte de anne karnına sürülen höllük, yeni doğmuş başka bir çocuğun evinin önüne gizlice dökülmekte, çocuğun ölüm ihtimali yeni doğmuş başka bir çocuğa geçirilmektedir (Örnek, 1966: 64-68).

Campbell'e (2013: 35-36) göre insanlık tarihin başlangıcından günümüze kötülükle ilişkilendirilen tüm gerçeklikleri bireyden ve gruptan uzaklaştırmak için kötülüğü kovma ritüelleri yapılır. İnsanoğlunun saflık konusundaki takıntısının bir sonucu olarak icat edilen bu ritüellerde, günahlar da sahibinden başka bir varlığa veya nesneye geçebilen somut bir varlık gibi tahayyül edilmektedir Kültürlerarası alanda gönüllülük ve/veya zorunluluk temelinde insanların; belirli hayvanların; taş, su vb nesnelerin; bitki türlerinin kötülüğün transferi için kullanıldığ görülür ${ }^{8}$. Taoistler yeni doğan çocuklar için tahta ikonlar yapar, çocuğun hastalanmaması için bu ikonları mabedlerin kapısından geçirir (Van Gennep, 1969: 57-58). Madakaskarlılar, Estonyalılar, Slovaklar, Bulgarlar, Fransızlar sıkıntı, hastalık ve belaları ağaçlara; Sumatralı Battalar kırlangıçlara, Yahudiler ve Cezayirli Müslümanlar kuşlara; Çinliler uçurtmalara; Faslılar kara domuzlara; Araplar da develere aktarır (Frazer, 1913: 1-59). 
Geçiş dönemi ritüelleri kapsamında kara talihin transferi de bu açıdan ele alınmalıdır. "Temasa dayalı ritüellerde doğal veya sonradan kazanılan özelliklerin geçirgenliği ve aktarılabilir olduğu düşüncesi vardır. Fiziksel temasla bir kişi, varlık veya nesneye belirli bir mesafede dokunarak, yaklaşarak bu özellikler karşı tarafa aktarılabilir” (Van Gennep, 1969: 7). Asmaları ağlatan kadınlar örneğinde menopozun orta yaş geçiş dönemi olması, gençlik döneminin de geride bırakıldığının ritüelle kabullenilmesi anlamına gelmektedir. Bu bağlamda, çocukluk ve gençlik evresinin hem fiziksel hem de duygusal anlamda dayanıklılıkla ilişkilendirildiği görülmektedir:

\begin{abstract}
"Derler ki 'elek geldi un bitti, kocam uslandı ömür bitti'. Her şey gençlikte olsun. Giyinmek, süslenmek de sıkıntı ve dert de. İki kaynanam vardı, kocam eve uğramazdı. On altı yaşında geldim bu eve. Demir çubuklarla dayak yer, bir de komşunun geliniyle çarşıya kaçar gezerdik. Şimdi olsa yatak döşek yatarsın değil mi? Gençlikte vız geliyor. Kocam üstüme kuma getirdi ona da dayandım. O da hastalandı, ona da baktım. Şimdi olsa bakamam. Gençken dayanırsın, aklın yok. Yaşlanınca akıl var, bağlasalar bu çilenin içinde durmazsın. O yüzden ne olacaksa gençken olsun. Yaşlıyken insan el üstünde tutulmak ister. Sırtını yaslayıp, dünyayı seyretmek ister...” (Altın, 2021).
\end{abstract}

Araştırma sahasında mutluluk, refah ve sağlık ömrün ya ilk ya da ikinci yarısında kadınlara bağışlanan bir ayrıcalık olarak görülmektedir. Menopoz da kadın ömrünü ortadan ikiye ayıran bir geçiş dönemi olarak eşik özelliği taşımaktadır. Bu bağlamda mülakat sırasında $\mathrm{H}$. Orhan (2021) "kadın kısmı ya baştan güler ya da sondan. İkisinde de güleni hiç görmedim" sözlerini doğrulamak için sayısız örnek vermektedir. Bu örneklerden birinde pre-menopoz evresindeki bir komşusunun erken ölümünü de asma ağlatmamış olmasıyla ilişkilendirmektedir.

Pre-menopoz evresi, eşik olarak düşünüldüğünde geçiş dönemi post-menopoz evresine denk düşmektedir. Böylece eşikte bir süre bekleyen kadın asma ağlatma ritüeliyle hayatın yeni evresine geçişini tanıklar huzurunda gerçekleştirmektedir. "Zaman ve mekân gözetmeksizin tüm toplumlarda iki temel ayrım vardır. İlki kadın ve erkek; ikincisi kutsal ve sekülerdir. Hem birey hem de toplum için hayat ayrılıklar, birleşmeler, dönüşmelerin; doğum ve ölüm arasında olup bitenler anlamına gelir. Bu bakımdan hayat geçilmesi gereken eşiklerle doludur" (Van Gennep, 1969: 189).

Asmaları ağlatan kadınlar, menopozla hayatlarının ikinci baharına geçiş yaparken asmayı ağlatarak bu evrede yaşamaları muhtemel sıkıntı, dert, musibet ve hastalıkları da asmaya aktarmaktadırlar. İkinci bahar yakıştırması da bu bağlamda hem gerçekliğe hem de gerçekliğin üstünün zarif bir yakıştırmayla örtülmesine de işaret eder. "Ritüellerin kucakladığg gerçeklikler insanların doğrudan yüzleşmekten kaçınabildikleri ortamlar yaratırken bile, gerçekliğe işaret eden ikircikli sembolik eylemlerdir" (Schechner, 2015: 261).

Ritüel sözlerindeki izin ve gönül alma, özür dileme, açıklamalar asmanın kötü kara bahtın transferi için seçilmiş varlık olduğunu göstermektedir. Malinowski'nin ifadesiyle ritüele eşlik eden sözler bir çeşit beyan, ümit ve arzu ifade edilenin vasıtaları ve tavsiye formlarıdır (1935: 248). Bir yönüyle temas büyüsünü de çağrıştıran ritüel eylemde, asmayla temas sırasinda hem mevcut hem de gelecekteki sıkıntılar asmaya transfer edilmektedir. 


\section{Sonuç}

Folklor halkın antik zamanlarda geliştirdiği bilgi kadar, bunlardan ilham alan yeni uygulamaları da içerir. Eski köye yeni adet getirilemeyeceğinden, görece yeni olan geçmişle bağı kurularak bugüne adapte edilir. İnsan, doğum ve ölüm arasındaki zamanda fizyolojik, duygusal ve sosyal dönüm noktalarına sembolik anlamlar yükler. Geçiş dönemi ritüelleri bireyin belirli bir süre eşikte bekledikten sonra, yeni bir sosyal hale geçişini kutlamak, ilan etmek, onaylamak için düzenlenen sosyal dramatik olaylardır. Ritüellerde geçiş döneminin bireye sosyal hak ve sorumlulukları tanımlanırken; yaş ve cinsiyet paralelinde kimi ayrıcalıklar sunulur veya kısıtlamalar getirilir. Sosyal bir sözleşme olarak geçiş dönemi ritüelleri bu ayrıcalık ve kısıtlamaları duyurduğu gibi, onların meşru gerekçelerini de sosyal olarak tanımlar. Geçiş dönemi ritüelleri bu nedenlerle bir topluluğun yaş ve cinsiyetle ilgili değerler sisteminin dramatik kılavuzlarıdır. 19. Yüzyılda açıkça geçiş dönemi olarak tanımlanan menopoz, kadın hayatının orta yaştan sonraki evresine geçişini temsil eden dönemdir.

Kadın hayatının ortalama üçte birlik kısmı post-menopoz evresinde geçmektedir. Bu bağlamda pre-menopoz evresi menopoz geçiş döneminin eşiğidir. Eşikte, kadın fiziksel, ruhsal ve sosyal anlamda kırılgan, savunmasız ve stresli haliyle geçiş dönemine hazırlanmaktadır. Kültür merkezli çalışmalar, kadının menopozu anlamlandırmasında ve deneyimlemesinde kültürün etkin olduğunu göstermektedir. Menstrüasyon döngüsü ve kadın korkusuyla ilişkilendirilen toplumsal cinsiyet rollerine bağı tabuların kadınların gündelik hayatını ve kutsalla ilişkisini düzenlediği kültürlerde, menopozun kadına ayrıcalıklar getirdiği görülmektedir. Menopozla kadın örtünmeden, yiyecek içecek hazırlamaya kadar bir dizi alanda menstrüasyonla ilişkili tabulardan görece bağımsızlaşmaktadır. Anadolu Türk folklorunda menopozun yakın zamanlarda keşfedilen bir geçiş dönemi olduğu akılda tutulduğunda, post-menopozu takiben icra edilen asma ağlatma ritüelinin de icat edildiği görülür. Kadınlar bu geleneği icat ederken, eski bir geleneği menopoza uyarlayarak güncellemiştir. 90’1 yıllarda estetik kayg1larla genç kızlar için icra edilen asma ağlatma geleneği milenyumda menopoza giren kadınlar için icra edilmektedir. Asma ağlatma ritüeli özü itibariyle Kastamonulu göçmen kadınlar tarafından Karabük'e taşınmış, iş̧̧i sınıfına mensup aileler arasında belirli mahallelerde icra edilmektedir. Bu da kültürleşme, ritüelin zaman ve mekânla sınırlandırılamamasıyla ilgilidir. Nitekim bu gelenek zamanın bir noktasında icraya katılan ve faydasını deneyimleyen kadınlarca hem Anadolu'nun başka şehirlerine hem de yurt dışına da taşınmıştır. Geleneğin özgün mahallinden Fransa'ya göç eden bir kaynak kişinin, bahçesindeki asmayı hemşerileri için ağlatıyor olması da bunun delilidir. Ritüeli icra eden kadın sosyal hiyerarşi içinde yaşına göre değil hayatta karşılaştı̆̆ sıkıntı ve sınamaların şiddetine göre seçilmektedir. Çocuk, eş, hastalık, yoksulluk, ailenin yaşlılarının bakımını üstlenmek gibi belirli parametreleri olan çile kadının grup içindeki hiyerarşik yerini belirlemektedir. Kaynak kişiler bu gerçekliği anlatırken bir atasözünü referans göstermektedir: "Akıl yaşta değil baştadır". Ritüel, talep üzerine gerçekleştirilmektedir. Post menopoz evresindeki bir kadın, bahçesinde uygun türde asması olan evlerin hanımlarından kendileri için asma ağlatılmasını istemektedir. Ritüelde ağlatılacak asma, meyveden kesilmiş bir asma ağacı olmak zorundadır. Bu tür asma ile me- 
nopoza girmiş kadının üretkenlik, doğurganlık noktasında birbiriyle özdeşleştirilmektedir. Ritüel, asma henüz yapraklanmaya başlamadan evvel, güneş yükselirken icra edilmektedir. Güneşin yükselmesi ve kadının bahtı arasında da bağ kurulmaktadır. Çünkü kadınlar hayatlarını menopoz öncesi ve sonrası olarak iki bölüme ayırmakta, menopoz sonrasında mutlu, sağlıklı, rahat ve refah içinde bir ömür geçirmek için asmayı ağlatmaktadır. Asma ağlatılırken söylenen "ben çok ağladım, bundan sonra sen ağla", "sana hesap yoktur; ben hem dünyada hem ahırette çekiyorum". "Ben de gün görmek istiyorum" gibi sözlerin ritüel söz dizimi içinde söylenmesi menopoz sonrası tüm sıkıntı ve dertlerin asmaya aktarılmasını temsil eder. Asma ağlatılırken, asma ağacından sızan gözyaşları da kadının bu ritüeli takiben akıtmamayı umduğu göz yaşlarıdır. Bu gözyaşı, menopozlu kadın ikinci bahar olarak adlandırdığı bu yeni yaşam evresinde son bir kez dökülen kutsal gözyaşıdır. Ritüeli takiben asmanın gözyaşının kadınların saçlarının bakımında kullanılması, bu işlemden artan göz yaşının ayak değmeyecek bir yere dökülmesi de onun kutsallığ ile ilişkilidir. Ritüelde asmanın yakınında duran menopozlu kadınlar ve uzaktan seyreden genç kadınların ritüele katılımı, bu ritüelin gelecekte de icra edileceğine olan inancımızı kuvvetlendirmektedir.

\section{Notlar}

1 Bu araştırma Bartın Üniversitesi Kadın Sorunları Uygulama ve Araştırma Merkezi tarafından desteklenmektedir.

2 Araştırma sahasının yerel dilinde ağlaklık, sebepsiz ağlamak anlamına gelmektedir.

3 Araştırma sahasının yerel dilinde ufalma, boyun ve bedenin küçülmesi anlamına gelmektedir.

4 Adetli kadınlara yönelik tabular hakkında kültürler arası örnekler için bakınız: Baskin, 1985: 3-18; Balzer, 1981: 850; Bededict, 2003: 47; Douglas, 1984: 145-148, 154; Durkheim, 1915: 304, 310, 380; Erdentuğ, 1959 : 39; Lowie, 1920: 203; Melby vd. 2005: 495-496) .

5 Araştırma sahasının yerel dilinde üstü kirli olmak, adetli olmak anlamına gelmektedir. "Üstü kirlenmek" ifadesi N. Erdentuğ’da (1968: 83) “başı kirlenmek” şeklinde görülmektedir.

6 Anadolu geçiş dönemleri bağlamında Perşembe gününün Cuma olarak adlandırılması, kutsal sayılması hakkında bakını: (Boratav, 2013: 151; Veren, 2019: 41-42).

7 Menopozlu kadınların toplumsal cinsiyet bağlamında erkeklerle eşitlendiği, cinsiyetinin erkek cinsiyeti içinde çözüldüğ̈̈ kültürler arası örnekler için bakınız: (Baskin, 1985: 3-18; Durkheim, 1915: 303; Erdentuğ, 1959: 39; Malinowski 1992a: 32, 64; Lowie, 1920: 264).

8 Kötülüğün insanlara; taşlara; hayvanlara; ağaçlara aktarılması hakkında bakınız: (Frazer, 1913: 5-7; 8-30; 31-37 ve 54-59; Ülkütaşır, 1974: 51).

\section{Kaynakça}

Abrahams, R. D. (1977). Toward an enactment-centered theory of folklore. In (W. R. Bascom. Ed.) Frontiers of folklore (79-120). American Association for the Advancement of Science.

Balzer, M. M. (1981). Rituals of gender identity: Markers of Siberian Khanty etnicity, status, and belief. American Anthropologist, 83(4), 850-867.

Baskin, J. (1985). The separation of women in rabbinic Judaism. In (Y. Y. Haddah and E. B. Findly. Ed.) Women, religion, and social change (3-18). State University of New York.

Bell, C. (1997). Ritual: Perspectives and dimensions. Oxford University.

Benedict, R. (2003). Kültür kalıpları (N. Şarman, Çev.) Payel.

Boratav, P. N. (2013). 100 soruda Türk folkloru. BilgeSu. 
Campbell, C. (2013). Günah keçisi: Başkalarının suçlarının tarihi. (G. Kastamonulu. Çev.) İstanbul: Ayrintı.

Carter, D. (2005). Living in virtual communities: An etnography of human relationship in cyberspace. Information, Communication \& Society, 8 (2), 148-167.

Connerton, P. (1999). Toplumlar nasıl anımsar?. (A. Şener. Çev.) İstanbul: Ayrıntı.

Dillaway, H. E. (2005). Menopause is good old: Women's thoughts about reproductive aging. Gender And Society, 19(3), 398-717. DOI: 10.1177/ 0891243204271350.

Dorson, R. M. (1970). Is There a folk in the City? Journal of American Folklore, 83, 185-216.

Douglas, M. (1984). Purity and danger: An analysis of the concepts of pollution and taboo. Routledge.

Durkheim, É. (1915). The elementary forms of the religious life : A study in religious sociology (J. W. Swain, Trans.) MacMillan.

Erdentuğ, N. (1959). Sün köyünün etnolojik tetkiki. Ayyıldız.

Erdentuğ, N. (1968). Hal köyünün etnolojik tetkiki. Ayyıldız.

Evren, A. (1952). Konya'da ocaklar, 1rvasalar, tekkeler II. TFA, 30, 476-478.

Fogelin, L. (2007). The archaeology of religious ritual. The Annual Review Of Anthropology, 36, 55-71. https:// /doi/10.1146/annurev.anthro. 36.081406.094425.

Frazer, J. G. (1913). The golden bough: A study in magic and religion (Third Edition, Vol. 4 of 12, The Scapegoat). MacMillan.

Goody, J. (2010). Myth, ritual and the oral. Cambridge University.

Hobsbawn, E. (2009). Introduction: Inventing tradition. In (E. Hobsbawn and T. Ranger. Ed.) The invention of tradition (1-15). Cambridge University.

Jassim, G. A. ve Q. Alsboul (2008). Attitudes of Bahraini women towards the menopause: Implications for health care policy. Maturitas, 59, 358-372. doi:10.1016/j.maturitas.2008.03.014.

Jones, E. K. , J. R. Jurgerson, J. M. Katzenellenbogen and S. C. Thompson (2012). Menopause and the influence of culture: Another gap for indigenous Australian women. BMC Women's Health, 12(43), 1-10. https://doi.org/10.1186/1472-6874-12-43.

Kapchan, D. (1995). Moroccon women's body signs. In (K. Young. Ed.) Body lore (3-35). The University of Tennessee.

Koşay, H. Z. (1939). Etnoğrafya ve folklor kılavuzu. Ulusal.

Lowie, R. H. (1920). Primitive society. Horace Liveright.

Lukes, S. (1975). Political ritual and social integration. Sociology, 9 (2), 289-308.

Malinowski, B. (1935). Coral gardens and their magic: The language of magic and gardening (Vol. II). Allen\&Unwin.

Malinowski, B. (1992a). Vahşilerin cinsel yaşamı (S. Özkal, Çev.) Kabalcı.

Malinowski, B. (1992b). Bilimsel bir kültür teorisi (S. Özkal, Çev.) Kabalc1.

Mauss, Marcel (2008). On prayer (S. Leslie, Trans.).Durkheim.

Melby, M. M. Lock and P. Kaufert (2005). Culture and symptom reporting at menopause. Human Reproduction Update, 11(5), 495-512. https://doi.org/10.1093/humupd/dmi018.

Nadel, S. F. (1954). Nupe Religion. Routledge.

Örnek, S. V. (1966). Sivas ve çevresindeki hayatın çeşitli safhalarıyla ilgili batıl inançların ve büyüsel işlemlerin etnolojik tetkiki. DTCF.

Petekçi, A. (1962). Bozkırda çocuk hastalıkları. TFA, 155, 2543.

Radcliffe-Brown, A. (1945). Religion and society. The Journal of the Royal Anthropological Institute of Great Britain and Ireland, 75(1/2), 33-43. https://doi.org/10.2307/2844278. 
Rappaport, R.A. (1992). Ritual. In R. Bauman(Ed.) Cultural Performances, and Popular Entertainments . 249-259. Oxford University.

Singh, A. and A.K. Arora (2005). Profile of menopausal women in rural North India. Climacteric, 8(2), 177-184. DOI: 10.1080/13697130500117920.

Thoms, W. J. (1965). Folklore. In (A. Dundes. Ed.), The study of folklore (4-7). Prentice Hall. (Reprinted from The antenæum (22 Ağustos 1846), 982, 862-863.

Turner, V. (1991). The ritual process: Structure and anti-structure. Cornell University.

Tylor, E. B. (1891a). Primitive culture researches into the development of mythology, philosophy, religion, language, art, and custom (Vol. I). John Murray.

Tylor, E. B. (1891b). Primitive culture researches into the development of mythology, philosophy, religion, language, art, and custom (Vol. II). John Murray.

Ülkütaşır, M. Ş. (1974). Sinop-Samsun ve çevrelerinde sağlık hastalık hakkındaki halk inançları ile halk hekimliğine ait bir araştırma kadrosu. I. Uluslararası Türk Folklor Semineri Bildirileri. 48-53. Başbakanlık Kültür Müsteşarlığı Milli Folklor Enstitüsü Müdürlüğü.

Van Gennep, A. (1969). The rites of passage (M. B. Vizedom and G. L. Caffee, Trans.) University of Chicago.

Veren, E. (2019). Kocakarı soğuklarından zemheriye Anadolu halk takvimi. Doğan Egmont.

Wilson, A. W. (1986). Documenting folklore. In (E. Oring. Ed.) Folk groups and folklore genres: An introduction (225-254). Utah State University.

Wilson, M. (1957). Rituals of kinship among the Nyakusa. Routledge.

Zeserson, J. M. (2001). How Japanese women talk about hot flushes: Implications for menopause research. Medical Anthropology Quaterly, 15(2), 189-205.

\section{Sözlü kaynaklar}

Altın, B. (2021). 1956 doğumlu, ilkokul mezunu, ev hanımı ile 26.03.2021 tarihinde Karabük'te yapılan görüşme.

Başdemir, D. (2021). 1948 doğumlu, okuma yazma yok, ev hanımı ile 26.03.2021 tarihinde Karabük’te yapılan görüşme.

Başkurt, S. (2021). 1954 doğumlu, ilkokul mezunu, ev hanımı ile 26.03.2021 tarihinde Karabük’te yapılan görüşme.

Berberoğlu, B. (2021b). 1949 doğumlu, ilkokul mezunu, ev hanımı ile 26.03.2021 tarihinde Karabük’te yapılan görüşme.

Berberoğlu, S. (2021a). 1977 doğumlu, yüksekokul mezunu, memure ile 25-26.03.2021 tarihinde Karabük'te yapılan görüşme.

Boz, M. . (2021). 1958 doğumlu, ilkokul mezunu, ev hanımı ile 26.03.2021 tarihinde Karabük’te yapılan görüşme.

Köse, M. (2020). 1963 doğumlu, okuma yazma yok, ev hanımı ile 04.04.2020 tarihinde Karabük’te yapılan görüşme.

Kurt, G. (2021). 1957 doğumlu, ilkokul mezunu, emekli ile 26.03.2021 tarihinde Karabük’te yapılan görüşme.

Orhan, Y. (2021). 1989 doğumlu, yüksekokul mezunu, ev hanımı ile 26.03.2021 tarihinde Karabük’te yapılan görüşme.

Taşkıran, S. (2020). 1957 doğumlu, ilkokul mezunu, ev hanımı ile 04. 04.2020 tarihinde Karabük’te yapılan görüşme. 
Acar, H. (2021). 1953 doğumlu, ilkokul mezunu, ev hanımı ile 18.03.2021 tarihinde Karabük’te yapılan görüşme.

Ekemen, P. (2021). 1963 doğumlu, ilkokul mezunu, ev hanımı ile 18.03.2021 tarihinde Karabük’te yapılan görüşme.

\section{Elektronik kaynaklar}

WHO (2021). Research on Menopause: Report of a WHO scientific group. https://apps.who.int/iris/ bitstream/handle/10665/41526/WHO_TRS_670.pdf?sequence=1\&isAllowed=y. (Erişim tarihi 02.02.2021). 
ETIKK KURUL KARARI :

T.C.

BARTIN UNIVERSITESI

Sosyal ve Beşeri Bilimleri Etik Kurulu

ONAY BELGESI

\begin{tabular}{|ll|}
\hline Protokol No: & \\
\cline { 2 - 2 } Protokol No: & $\begin{array}{l}\text { 2021-SBB-0059 } \\
\text { Araştrmanın Başlığı: }\end{array}$ \\
\cline { 2 - 2 } Proje Yürütücüsü: & $\begin{array}{l}\text { Anadolu Kadm Folklorunda Kara } \\
\text { Ratüeliyle Transferi:Asmaları Ağlatan } \\
\text { Kadmlar örneiği }\end{array}$ \\
\cline { 2 - 2 } Bavuru Formunun Geliş Tarih: & Hicran KARATAŞ \\
\cline { 2 - 2 } Karar Tarihi: & \begin{tabular}{l}
02.02 .2021 \\
\hline Toplantı No:
\end{tabular} \\
\hline
\end{tabular}

Bavuru dosyasmda etik sorun oluşturabilecek sorular/maddeler, süreçler ya da unsurlar bulunmadığından 12.03 .2021 tarihli ve 3 numaral toplantıda 2021-SBB-0059 numaralı başvuruya araştırma için ETIK KURUL ONAY belgesinin verilmesine oy birligi ile karar verilm iştir.

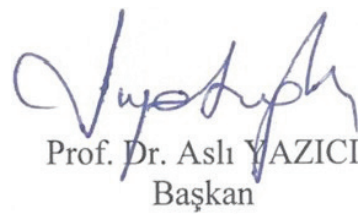

